\title{
Elementary Kinetic Numerical Simulation of Electrochemical CO Oxidation on Ni/YSZ Pattern Anodes
}

\author{
Vitaliy Yurkiv ${ }^{\mathrm{a}, \mathrm{c}}$, Annika Utz ${ }^{\mathrm{b}}$, André Weber $^{\mathrm{b}}$, Ellen Ivers-Tiffée ${ }^{\mathrm{b}}$, Hans-Robert Volpp ${ }^{\mathrm{a}}$ \\ Wolfgang G. Bessler ${ }^{\mathrm{c}}$ \\ a) Institute of Physical Chemistry, Heidelberg University, 69120 Heidelberg, Germany \\ b) Institut für Werkstoffe der Elektrotechnik (IWE) \\ Karlsruher Institut für Technologie (KIT), 76131 Karlsruhe, Germany \\ ${ }^{c}$ German Aerospace Centre (DLR), Institute of Technical Thermodynamics, 70569 \\ Stuttgart, Germany
}

\begin{abstract}
Results of a numerical simulation analysis of recent experimental data obtained in a comprehensive study of electrochemical $\mathrm{CO}$ oxidation on well-defined Ni/YSZ patterned model anodes [Utz et al. J. Power Sources, doi:10.1016/j.powsour. 20.10.056 (2010)] are presented. A computational model representing the coupled behavior of heterogeneous chemistry and electrochemistry in terms of elementary reactions was developed, which allows for a quantitative description of the complete experimental data set, which covers a wide range of $\mathrm{CO} / \mathrm{CO}_{2}$ gas compositions $\left(4.0 \cdot 10^{2}\right.$ $\mathrm{Pa} \leq p \mathrm{CO} \leq 5.1 \cdot 10^{4} \mathrm{~Pa}$ and $\left.9.5 \cdot 10^{2} \mathrm{~Pa} \leq p \mathrm{CO}_{2} \leq 9.2 \cdot 10^{4} \mathrm{~Pa}\right)$ and operating temperatures $(973 \mathrm{~K} \leq T \leq 1073 \mathrm{~K})$. In the framework of the presented model a direct mechanistic interpretation of the experimentally observed electrochemical characteristics is obtained.
\end{abstract}

\section{Introduction}

Due to the geometrical complexity of nickel and yttria-stabilized zirconia (Ni/YSZ) composites, which are commonly used as anodes in solid oxide fuel cells (SOFCs), the quantitative numerical simulation of the chemically reacting flow problem in such systems represents a formidable task. In particular, the strong nonlinear interaction of porous media gas transport with both electrochemical charge transfer reactions and thermal heterogeneous chemistry has to be incorporated (1). As a consequence, the elucidation of the electrochemical charge transfer reaction mechanism along with a quantitative determination of the rate coefficients of the involved elementary reaction steps requires a numerical modeling approach in combination with electrochemical characterization measurements performed for geometrically well-defined model anode structures. This approach has recently been successfully applied to derive detailed elementary reaction mechanisms comprising both charge transfer and thermal heterogeneous elementary reactions underlying the electrochemical oxidation of $\mathrm{H}_{2}(2-5)$ and $\mathrm{CO}(6)$.

In a recent study, we have investigated $\mathrm{CO}$ oxidation using surface science techniques such as temperature-programmed desorption and temperature-programmed reaction along with numerical simulations. A thermodynamically consistent kinetics data set for $\mathrm{CO}$ 
adsorption/desorption and heterogeneous $\mathrm{CO}$ oxidation on both $\mathrm{Ni}$ and YSZ surfaces was derived. Based on these data, an elementary kinetic reaction mechanism of the electrochemical $\mathrm{CO}$ oxidation at Ni/YSZ anode systems was developed (6), which was validated against experimental electrochemical data (steady-state polarization curves and electrochemical impedance spectra) measured by Lauvstad et al. (7) for a Ni-point/YSZ model anode under different $\mathrm{CO} / \mathrm{CO}_{2}$ atmospheres. However, as the latter electrochemical characterization experiments were performed for only one single operating temperature $(T=1149 \mathrm{~K})$, no information about the temperature dependence of the rate constants of the charge transfer reactions occurring at the three-phase boundary (TPB) of $\mathrm{CO} / \mathrm{CO}_{2}$ gas-phase, Ni electrode, and the YSZ electrolyte could be derived in Ref. (6).

Only recently were experiments performed by Utz et al. (8), in which the $\mathrm{CO} / \mathrm{CO}_{2}$ partial pressure dependence of well-defined Ni/YSZ SOFC pattern model anode characteristics was investigated over an extended operating temperature range $(973 \mathrm{~K} \leq T$ $\leq 1073 \mathrm{~K})$. In these experiments special care was taken, by carefully choosing appropriate $p \mathrm{CO}$ and $\mathrm{pCO}_{2}$ partial pressure ranges, to avoid both oxidation of the $\mathrm{Ni}$ electrode material as well as carbon deposition on the Ni surface due to the Boudouard reaction. In addition, in contrast to previously-reported $\mathrm{CO}$ oxidation studies on $\mathrm{Ni} / \mathrm{YSZ}$ pattern model anodes (9), which suffered from ill-defined TPB lengths (due to uncontrolled $\mathrm{Ni}$ island formation during the course of the experiments), the experiments of Utz et al. (8) were accompanied by thorough pre- and post- test analysis of the Ni pattern structures (10-13), which allowed for a quantitative determination of the actual TPB length as well as the impurity content of the sample. Hence, the results of Utz et al. can be at present regarded as the most detailed experimental investigations of the electrochemical $\mathrm{CO}$ oxidation over Ni/YSZ pattern model anodes.

In the present contribution the results of a detailed numerical modeling study of the electrochemical CO oxidation data of Utz et al. (8) is presented. The previously developed elementary reaction mechanism [6] is applied for a mechanistic interpretation of the experimentally observed electrochemical behavior in terms of microscopic heterogeneous reaction pathways on $\mathrm{Ni}$ and YSZ and rate-determining charge transfer steps taking place at the TPB. Finally a unified validated reaction mechanism is presented which allows for a quantitative and consistent description of both the previous experimental results of Lauvstad et al. (7) as well as the recent results obtained by Utz et al. (8).

\section{Theoretical and Experimental Methodology}

$\underline{\text { Modeling and Simulation }}$

The numerical simulations of the $\mathrm{CO}$ electrochemical oxidation were performed using the software package DENIS $(2,14)$, which is based on (i) a molecular-scale elementary kinetic approach for the thermodynamically consistent description of electrochemistry and heterogeneous surface chemistry, (ii) charge transfer reactions described as surface spillover reactions at the TPB, and (iii) surface diffusion on the Ni electrode and YSZ electrolyte surfaces described in one dimension (1D) perpendicular to the TPB line. This modeling framework has been used in our previous study of $\mathrm{CO}$ oxidation at a Ni/YSZ 
point model anode (6). The model equations are outlined in detail in Ref. (2). Electrochemical impedance spectra were simulated using the potential step and current relaxation technique described in Ref. (15). The impedance is obtained in the frequency domain by applying a Fourier transform to the resulting time-domain traces of current and potential. The LIMEX solver (16) is used for the numerical integration of the reaction-diffusion equation system. In the present study of the electrochemical CO oxidation measurements at a Ni/YSZ pattern anode (8) our previously derived elementary kinetic mechanism, which is given in Ref. (6) along with the respective reaction kinetics and thermodynamic datasets (Table I and Table II of Ref. (6)), was used as parameter base.

\section{Experiments}

The experimental setup and methodology was described in detail elsewhere (8). In the experiments, Ni/YSZ pattern anodes with an area of $10.25 \times 10.25 \mathrm{~mm}^{2}$ were used which were fabricated on 8.5 mol-\% polycrystalline $\mathrm{Y}_{2} \mathrm{O}_{3}$-stabilized $\mathrm{ZrO}_{2}$ (YSZ) substrates following the procedure described in (17). The design of the Ni pattern is composed of an area of $9.25 \times 9.25 \mathrm{~mm}^{2}$ with parallel Ni stripes with $25 \mu \mathrm{m}$ width, a spacing of $160 \mu \mathrm{m}$ and a thickness of $800 \mathrm{~nm}$. An additional frame with $500 \mu \mathrm{m}$ width assures contacting of all stripes resulting in an actual triple phase boundary length of $l_{\mathrm{TPB}}=1.3 \mathrm{~m} / \mathrm{cm}^{2}$ in the experiments as determined by SEM measurements. The geometric features of Ni/YSZ pattern anode used in the electrochemical characterization studies are summarized in Table I. As counter electrode, a screen-printed Ni/YSZ cermet anode was employed, the preparation of which was described previously (18). The counter electrode was applied to the substrate prior to Ni anode patterning.

Electrochemical impedance spectra were recorded for different $\mathrm{CO} / \mathrm{CO}_{2} / \mathrm{N}_{2}$ gas mixtures at open circuit over a frequency range of $100 \mathrm{mHz}-1 \mathrm{MHz}$ with a voltage stimulus of $10 \mathrm{mV}$ to derive the line-specific charge transfer resistance, which will be denoted as LSR $\mathrm{CT}_{\mathrm{T}}$ in the following (for further experimental details see (8) and references therein). Values of $\mathrm{LSR}_{\mathrm{CT}}$ were calculated by multiplication of the charge transfer contribution to the polarization resistance (denoted as $\left.R_{\mathrm{CT}}\right)$, the actual TPB length $\left(l_{\mathrm{TPB}}\right)$ and the electrode area $(A)$, via the following equation:

$$
\mathrm{LSR}_{\mathrm{CT}}=R_{\mathrm{CT}} \cdot l_{\mathrm{TPB}} \cdot A \text {. }
$$

In the electrochemical characterization experiments the partial pressures of $\mathrm{CO}$ and $\mathrm{CO}_{2}$ were varied in the range of $4.0 \cdot 10^{2} \mathrm{~Pa} \leq p \mathrm{CO} \leq 5.1 \cdot 10^{4} \mathrm{~Pa}$ and $9.5 \cdot 10^{2} \mathrm{~Pa} \leq p \mathrm{CO}_{2} \leq$ $9.2 \cdot 10^{4} \mathrm{~Pa}$, respectively. The investigated operating temperature range was $973 \mathrm{~K} \leq T \leq$ $1073 \mathrm{~K}$. The conditions were chosen to avoid Ni oxidation and carbon formation due to the Boudouard reaction. The stability of the Ni patterned anodes used in the experiments was controlled by pre- and post-test SEM analysis as described in detail in (8).

TABLE I: Geometry features of Ni/YSZ pattern anodes developed by Utz et al. (8)

\begin{tabular}{lll}
\hline Parameter & Symbol & Value \\
\hline Thickness of electrolyte & $d_{\text {elyt }}$ & $200 \mu \mathrm{m}$ \\
Thickness of nickel & $d_{\text {elect }}$ & $0.8 \mu \mathrm{m}$ \\
Width of free YSZ area & $d_{\text {YsZ }}$ & $160 \mu \mathrm{m}$ \\
Width of Ni stripe & $d_{\mathrm{Ni}}$ & $25 \mu \mathrm{m}$ \\
Length of TPB & $l_{\mathrm{TPB}}$ & $1.3 \mathrm{~m} / \mathrm{cm}^{2}$ \\
Electrode area & $A$ & $1 \mathrm{~cm}^{2}$ \\
\hline
\end{tabular}




\section{Results and Discussion}

\section{Elementary Kinetic Reaction Mechanism}

The elementary reactions included in the present model in order to resolve the global electrochemical CO oxidation reaction,

$$
\mathrm{CO}+\mathrm{O}_{\mathrm{O}, \mathrm{YSZ}}^{\mathrm{x}} \rightleftharpoons \mathrm{CO}_{2}+\mathrm{V}_{\mathrm{O}, \mathrm{YSZ}}^{\bullet}+2 e_{\mathrm{Ni}}^{-}
$$

are listed in Table II and are schematically depicted in Fig. 1. The mechanism contains two gas-phase species $\left(\mathrm{CO}, \mathrm{CO}_{2}\right)$, four $\mathrm{Ni}$ surface species $\left(\square_{\mathrm{Ni}}, \mathrm{CO}_{\mathrm{Ni}}, \mathrm{CO}_{2, \mathrm{Ni}}, \mathrm{O}_{\mathrm{Ni}}\right)$, five YSZ surface species ( $\square$ YsZ, $\mathrm{CO}_{\mathrm{YSZ}}, \mathrm{O}_{\mathrm{YSZ}}^{1-}, \mathrm{O}_{\mathrm{YSZ}}^{2-}, \mathrm{O}_{\mathrm{YSZ}}$ ) and two YSZ bulk species $\left(\mathrm{O}_{\mathrm{O} \text { YSZ }}^{\mathrm{X}}\right.$ and $\mathrm{V}_{\mathrm{O} \text { YSZ }}^{\bullet \bullet}$ ), which in Kröger-Vink notation (19) stand for bulk YSZ oxygen ions and vacancies, respectively. The species denoted as $\square_{\mathrm{YSZ}}$ and $\square_{\mathrm{Ni}}$ represent free surface adsorption sites on YSZ and Ni.

The thermal heterogeneous reaction mechanism for the $\mathrm{Ni}$ surface includes $\mathrm{CO}$ and $\mathrm{CO}_{2}$ adsorption/desorption (R1 and R2) as well as $\mathrm{CO}$ oxidation steps via an Eley-Rideal (ER) reaction step (R3) and via a Langmuir-Hinshelwood (LH) reaction step (R4). The reaction mechanism for the YSZ electrolyte surface includes $\mathrm{CO}$ adsorption/desorption (R5) and a heterogeneous CO oxidation step, which according to the TPR experiments of Ref. [6] proceeds predominately via an Eley-Rideal (ER) reaction step (R6) where gasphase $\mathrm{CO}$ directly reacts with YSZ oxygen surface atoms to yield gas-phase $\mathrm{CO}_{2}$. The $1 \mathrm{D}$ reaction-diffusion model, which includes diffusion of the $\mathrm{CO}, \mathrm{CO}_{2}$ and $\mathrm{O}$ surface species on $\mathrm{Ni}$ and YSZ perpendicular to the TPB, was taken from our previous work [6], along with the respective diffusion coefficients. The YSZ oxygen ion bulk-surface exchange is included via reaction $\mathrm{R} 7$.

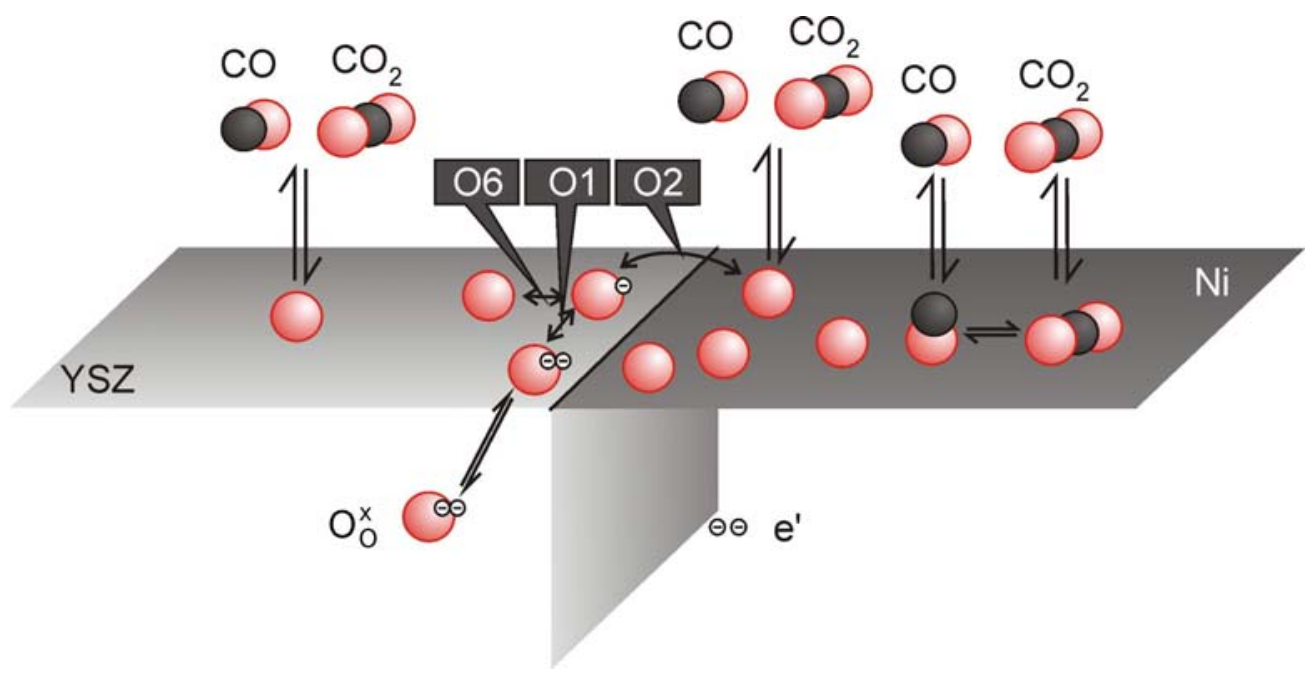

Figure 1. Schematic illustration of the heterogeneous reaction mechanism and the three different elementary charge-transfer reaction steps (O1, O2, O6, following the nomenclature of Refs. $(2,6))$ taking place at the three-phase boundary of Ni, YSZ and gas phase. 
The charge-transfer (CT) mechanism derived in the present study comprises three CT reaction steps (denoted as O1, O2, and $\mathrm{O} 6$ in Fig. 1 and Table II), all of which take place at the TPB line. The CT reaction nomenclature follows that of our previous work on electrochemical $\mathrm{CO}$ oxidation at a Ni/YSZ point anode system, where five different $(\mathrm{O} 1$ O5) CT reaction steps were tested [6]. As described in detail in Ref. (6), only the reaction sequence $\mathrm{O} 1$ followed by $\mathrm{O} 2$ (denoted as $\mathrm{O} 1+\mathrm{O} 2$ ) resulted in a quantitative agreement with the point electrode experimental data of Lauvstad et al. (7). In this reaction sequence, the first reaction $\mathrm{O} 1$ represents a single electron oxidation step of an $\mathrm{O}_{\mathrm{YSZ}}^{2-}$ species, followed by a second $\mathrm{CT}$ reaction, $\mathrm{O} 2$, which represent a spillover of an $\mathrm{O}_{\mathrm{YSZ}}^{1-}$ ion onto the Ni electrode surface with a simultaneous electron transfer to the Ni. The additional CT reaction step, O6, derived in the present simulation study describes the discharge of an YSZ oxygen ion, $\mathrm{O}_{\mathrm{YSZ}}^{1-}$, which proceeds by an electron transfer to the $\mathrm{Ni}$ electrode with the resulting YSZ oxygen atom, $\mathrm{O}_{Y S Z}$, remaining on the YSZ electrolyte surface. The necessity for the implementation of the additional CT reaction (O6) is explained in the discussion of the experimentally observed pronounced influence of $\mathrm{CO} / \mathrm{CO}_{2}$ gasphase composition on the $\mathrm{LSR}_{\mathrm{CT}}$ value.

TABLE II. Summary of the kinetic parameters for the Ni and YSZ surface reactions (R1-7) and the electrochemical charge-transfer $(\mathrm{CT})$ reactions $(\mathrm{O} 1, \mathrm{O} 2, \mathrm{O})$. Ni and YSZ surface site densities are $6.1 \cdot 10^{-9}$ $\mathrm{mol} \cdot \mathrm{cm}^{-2}$ and $1.3 \cdot 10^{-9} \mathrm{~mol} \cdot \mathrm{cm}^{-2}$, respectively. Symmetry factors of the charge-transfer reaction are set to 0.5 . The parameters are: $k^{0}$ pre-exponential factor, $E^{\text {act }}$ Arrhenius activation energy, $s_{i}^{0}$ initial sticking coefficient. The symbols $\square_{\mathrm{Ni}}$ and $\square$ YsZ denote free surface sites on Ni and YSZ, respectively. The units of the pre-exponential factors of the $\mathrm{CT}$ reactions result from the formulation of the rate equations as described in detail in Ref. (2).

\begin{tabular}{|c|c|c|c|c|}
\hline No. & Reaction & $k^{0}\left(\right.$ or $\left.\mathrm{s}_{\mathrm{i}}^{0}\right)$ & $\left.\mathrm{l}^{-1}\right)$ & \\
\hline \multicolumn{5}{|c|}{ Ni surface reactions } \\
\hline $\mathrm{R} 1$ & $\mathrm{CO}+\square_{\mathrm{Ni}} \rightleftharpoons \mathrm{CO}_{\mathrm{Ni}}$ & $s_{i}^{0}=5.0 \cdot 10^{-1}$ & 0 & {$[6]$} \\
\hline $\mathrm{R} 2$ & $\mathrm{CO}_{2, \mathrm{Ni}} \rightleftharpoons \mathrm{CO}_{2}+\square_{\mathrm{Ni}}$ & $7.0 \cdot 10^{11} \mathrm{~s}^{-1}$ & 41 & {$[6]$} \\
\hline R3 & $\mathrm{CO}+\mathrm{O}_{\mathrm{Ni}} \rightleftharpoons \mathrm{CO}_{2}+\square_{\mathrm{Ni}}$ & $1.0 \cdot 10^{23} \mathrm{~cm}^{2} \cdot \mathrm{mol}^{-1} \cdot \mathrm{s}^{-1}$ & 188.0 & {$[20]$} \\
\hline $\mathrm{R} 4$ & $\mathrm{CO}_{\mathrm{Ni}}+\mathrm{O}_{\mathrm{Ni}} \rightleftharpoons \mathrm{CO}_{2, \mathrm{Ni}}+\square_{\mathrm{Ni}}$ & $2.0 \cdot 10^{19} \mathrm{~cm}^{2} \cdot \mathrm{mol}^{-1} \cdot \mathrm{s}^{-1}$ & 123.6 & {$[6]$} \\
\hline \multicolumn{5}{|c|}{ YSZ surface reactions } \\
\hline R5 & $\mathrm{CO}+\square_{\mathrm{YSZ}} \rightleftharpoons \mathrm{CO}_{\mathrm{YSZ}}$ & $S_{i}^{0}=4.0 \cdot 10^{-2}$ & 0 & {$[6]$} \\
\hline R6 & $\mathrm{CO}+\mathrm{O}_{\mathrm{YsZ}} \rightleftharpoons \mathrm{CO}_{2}+\square_{\mathrm{YsZ}}$ & $1.0 \cdot 10^{23} \mathrm{~cm}^{2} \cdot \mathrm{mol}^{-1} \cdot \mathrm{s}^{-1}$ & 115.1 & [20] \\
\hline R7 & $\mathrm{O}_{\mathrm{YSZ}}^{2-}+\mathrm{V}_{\mathrm{OYSZ}}^{\cdot \cdot} \rightleftharpoons \mathrm{O}_{\mathrm{O} Y S Z}^{\mathrm{X}}+\square_{\mathrm{YSZ}}$ & $1.6 \cdot 10^{22} \mathrm{~cm}^{2} \cdot \mathrm{mol}^{-1} \cdot \mathrm{s}^{-1}$ & 90.9 & {$[2]$} \\
\hline \multicolumn{5}{|c|}{ Charge-transfer $(\mathrm{CT})$ reactions } \\
\hline $\mathrm{O} 1$ & $\mathrm{O}_{\mathrm{YSZ}}^{2-} \rightleftharpoons \mathrm{O}_{\mathrm{YSZ}}^{1-}+\mathrm{e}_{\mathrm{Ni}}^{-}$ & $8.4 \cdot 10^{2} \mathrm{~mol} \cdot \mathrm{cm}^{-1} \cdot \mathrm{s}^{-1}$ & 75 & This work \\
\hline $\mathrm{O} 2$ & $\mathrm{O}_{\mathrm{YSZ}}^{1-}+\square_{\mathrm{Ni}} \rightleftharpoons \mathrm{O}_{\mathrm{Ni}}+\square_{\mathrm{YSZ}}+\mathrm{e}_{\mathrm{Ni}}^{-}$ & $3.5 \mathrm{~mol} \cdot \mathrm{cm}^{-1} \cdot \mathrm{s}^{-1}$ & 135 & This work \\
\hline O6 & $\mathrm{O}_{\mathrm{YSZ}}^{1-} \rightleftharpoons \mathrm{O}_{\mathrm{YSZ}}+\mathrm{e}_{\mathrm{Ni}}^{-}$ & $1.4 \cdot 10^{-1} \mathrm{~mol} \cdot \mathrm{cm}^{-1} \cdot \mathrm{s}^{-1}$ & 82 & This work \\
\hline
\end{tabular}


The model used in the present study further includes a description of the electrochemical double layer, where the double-layer capacitance $\left(C_{\mathrm{dl}}\right)$ is an additional model parameter. In the simulations, the $C_{\mathrm{dl}}$ value of the Ni/YSZ interface was $0.25 \mathrm{~F} \mathrm{~m}^{-}$ ${ }^{2}$, the temperature dependency of the double-layer capacitance of the Ni/YSZ interface was $8 \cdot 10^{-4} \mathrm{~F} \mathrm{~K}^{-1} \mathrm{~m}^{-2}$. The pre-exponential factor for bulk ion conductivity of the YSZ electrolyte was $3.6 \cdot 10^{7} \mathrm{~S} \mathrm{~K} \mathrm{~m}^{-4}$ and the activation energy was $90 \mathrm{~kJ} \mathrm{~mol}^{-1}$ (6).

\section{$\underline{\text { Influence of } \mathrm{CO} / \mathrm{CO}_{2}}$ Gas-Phase Composition}

In Fig. 2 the experimentally obtained values for $\operatorname{LSR}_{\mathrm{CT}}$ (open symbols) are plotted as a function of the $\mathrm{CO}$ partial pressure for an operating temperature of $1073 \mathrm{~K}$ and a fixed $\mathrm{CO}_{2}$ partial pressure of $2 \cdot 10^{4} \mathrm{~Pa}$. Obviously the $\mathrm{LSR}_{\mathrm{CT}}$ shows a pronounced dependence on the $\mathrm{CO}$ partial pressure with different slopes at high and low $p C O$ values and a broad minimum of $\mathrm{LSR}_{\mathrm{CT}}$ at a $p \mathrm{CO}$ value of ca. $10^{4} \mathrm{~Pa}$. In numerical simulations based on the previously derived consecutive $\mathrm{CT}$ reaction mechanism $(\mathrm{O} 1+\mathrm{O} 2)$, the experimentally observed minimum in $\mathrm{LSR}_{\mathrm{CT}}$ could not be reproduced, only the high $\mathrm{CO}$ partial pressure region (right to the $\mathrm{LSR}_{\mathrm{CT}}$ minimum) could be quantitatively described. This finding indicated the necessity for the inclusion of the additional CT reaction (O6). The simulation results for the full mechanism $(\mathrm{O} 1+\mathrm{O} 2+\mathrm{O} 6)$, parameterized as given in Table II, are shown as solid line in Fig. 2. The simulations agree quantitatively with the experiments over the complete investigated range of $\mathrm{CO}$ partial pressures.

The inclusion of $\mathrm{O} 6$ results in a mechanistic picture in which the actual $\mathrm{O}$ coverage on the Ni side of the TPB $\left(\theta_{\text {Ni-TPB-O }}\right)$ represents the key parameter, which induces the change in the experimentally determined LSR $_{\mathrm{CT}}$ slope. The value of $\theta_{\text {Ni-TPB-O }}$ is determined by the competition between oxygen buildup at the Ni TPB region (due to the spillover CT reaction step O2) and the heterogeneous $\mathrm{O}$ removal reactions on $\mathrm{Ni}$ (via $\mathrm{R} 3$ and R4), both of which depend on the $\mathrm{CO} / \mathrm{CO}_{2}$ gas composition. The present simulation study indicates that at sufficiently high $\mathrm{CO}$ partial pressures the overall charge transfer is occurs via the $\mathrm{O} 1+\mathrm{O} 2$ reactions while at low $\mathrm{CO}$ partial pressures the overall charge transfer occurs via the $\mathrm{O} 1+\mathrm{O} 6$, as the actual rate of the $\mathrm{O} 2$ spillover step strongly decreases with increasing $\theta_{\text {Ni-TPB-O }}$ due to site blocking.

In the framework of the extended CT reaction model, the minimum in the experimental $\mathrm{LSR}_{\mathrm{CT}}$ values could be quantitatively reproduced in numerical simulations (Fig. 2) employing the kinetics data set given in Table II. The calculations indicated that the change in slope (and hence the change in the $\mathrm{CT}$ reaction mechanism) occurs at a value of $\theta_{\mathrm{Ni} \text {-TPB-O }}=0.2$ which is achieved at $T=1073 \mathrm{~K}$ and $p \mathrm{CO}_{2}=2 \cdot 10^{4} \mathrm{~Pa}$ for a $\mathrm{CO}$ partial pressure of $p \mathrm{CO}=2 \cdot 10^{4} \mathrm{~Pa}$.

Additional concentration variations are shown in Figs. 3 and 4. Fig. 3 shows results for conditions where the partial pressure of $\mathrm{CO}_{2}$ was increased from $2 \cdot 10^{4} \mathrm{~Pa}$ to $5.1 \cdot 10^{4}$ $\mathrm{Pa}$. The observed minimum is shifted towards higher $\mathrm{CO}$ partial pressures. The simulations again agree quantitatively with the experiments. The oxygen coverage in this case increases to a value of 0.3 for $p \mathrm{CO}=1 \cdot 10^{4} \mathrm{~Pa}$. Fig. 4 shows results for varying $p \mathrm{CO}_{2}$ with constant partial pressure of $\mathrm{CO}$. This variation does not show a distinct minimum. The simulation results are once more in good agreement with the experiments. 


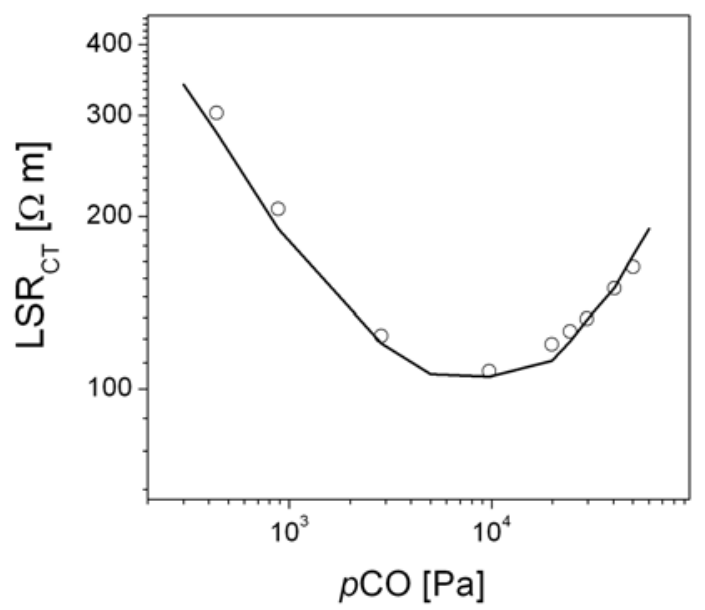

Figure 2. Experimental (open symbols) and simulated (solid line) line-specific CT resistance $\left(\mathrm{LSR}_{\mathrm{CT}}\right)$ of a Ni/YSZ pattern anode as a function of the $\mathrm{CO}$ partial pressure for a fixed $\mathrm{CO}_{2}$ partial pressure of $p \mathrm{CO}_{2}=2 \cdot 10^{4} \mathrm{~Pa}(T=1073 \mathrm{~K})$.

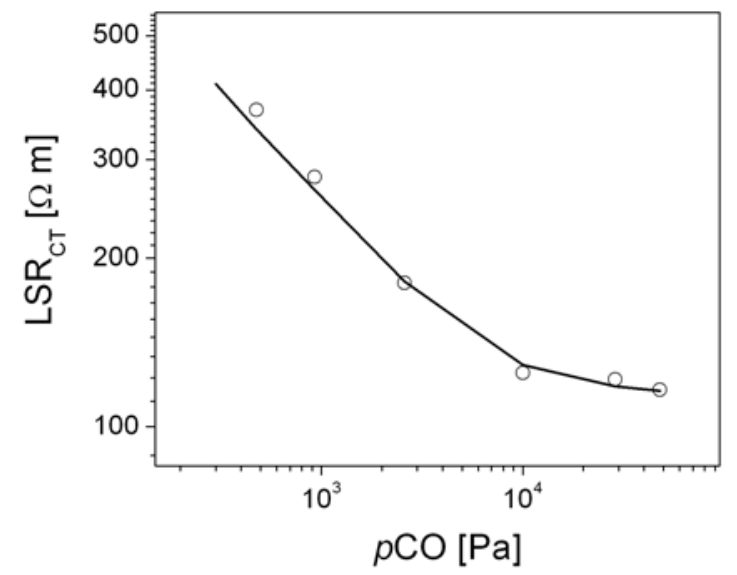

Figure 3. Experimental (open symbols) and simulated (solid line) line-specific resistance $\left(\mathrm{LSR}_{\mathrm{CT}}\right)$ of a Ni/YSZ pattern anode as a function of $\mathrm{CO}$ partial pressure for a $\mathrm{CO}_{2}$ partial pressure of $p \mathrm{CO}_{2}=5.1 \cdot 10^{4} \mathrm{~Pa}(T=1073 \mathrm{~K})$.

a)

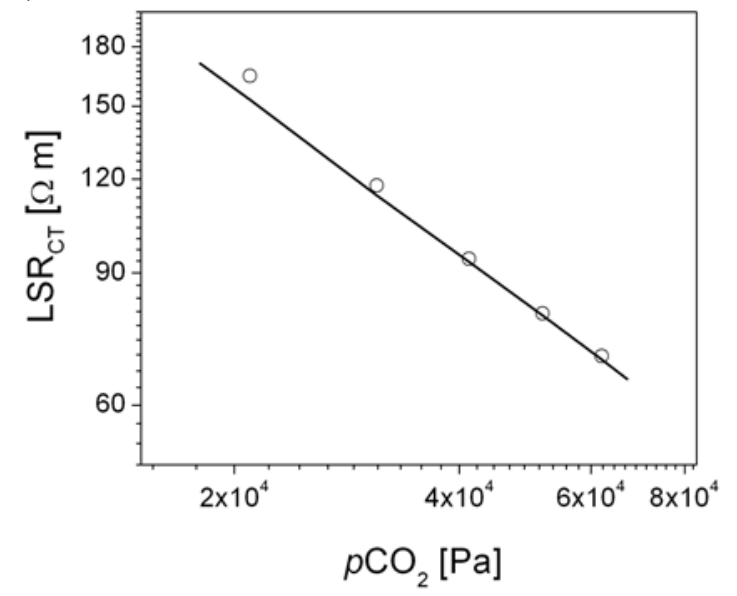

b)

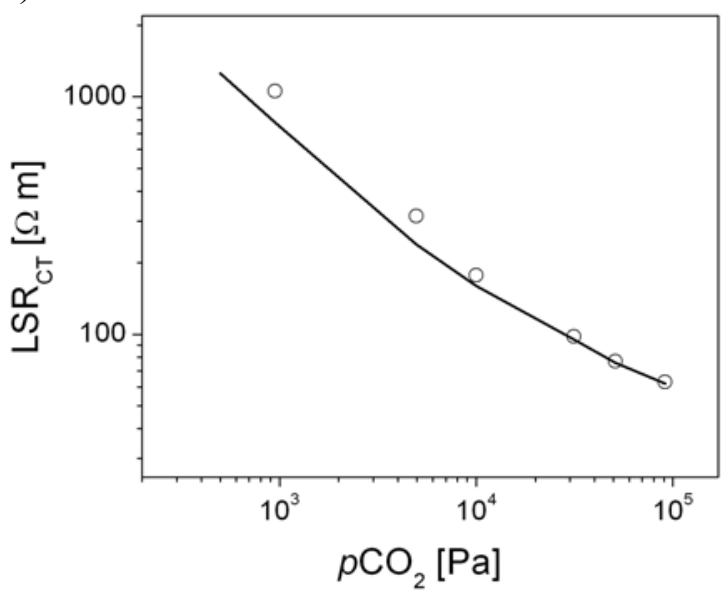

Figure 4. Experimental (open symbols) and simulated (solid line) line-specific resistance $\left(\mathrm{LSR}_{\mathrm{CT}}\right.$ ) of a Ni/YSZ pattern anode as a function of $\mathrm{CO}_{2}$ partial pressure for: a) $\mathrm{CO}$ partial pressure of $\left.3.9 \cdot 10^{4} \mathrm{~Pa}, \mathrm{~b}\right) \mathrm{CO}$ partial pressure of $1 \cdot 10^{4} \mathrm{~Pa}(T=1073 \mathrm{~K})$. 


\section{$\underline{\text { Influence of Temperature }}$}

The temperature dependence of $\mathrm{LSR}_{\mathrm{CT}}$ was measured and simulated for two different $\mathrm{CO}$ partial pressures of $p \mathrm{CO}=3 \cdot 10^{4} \mathrm{~Pa}$ and $p C O=9.2 \cdot 10^{2} \mathrm{~Pa}$, at a constant $\mathrm{CO}_{2}$ partial pressure of $\mathrm{pCO}_{2}$ of $2 \cdot 10^{4} \mathrm{~Pa}$. The comparison between the simulation (lines) and experimental results (open symbols) is shown in Fig. 5. Both the absolute values and the slope of the simulated $\mathrm{LSR}_{\mathrm{CT}}$ curves are in excellent agreement with the experimental data, demonstrating the ability of the $(\mathrm{O} 1+\mathrm{O} 2+\mathrm{O} 6) \mathrm{CT}$ mechanism to reproduce the electrochemical data over the entire $\mathrm{CO} / \mathrm{CO}_{2}$ gas composition and operating temperature range investigated in the experimental characterization studies.

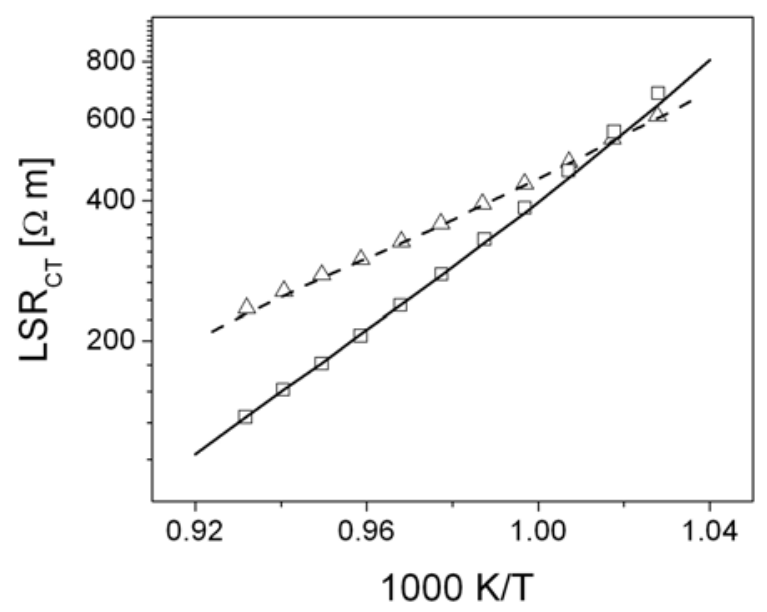

Figure 5. Experimental (open symbols) and simulated (lines) $\mathrm{LSR}_{\mathrm{CT}}$ versus inverse temperature at: solid line and respective open squares $p \mathrm{CO}=3 \cdot 10^{4} \mathrm{~Pa}, p \mathrm{CO}_{2}=2 \cdot 10^{4} \mathrm{~Pa}$; dashed line and respective open triangles $p \mathrm{CO}=9.2 \cdot 10^{2} \mathrm{~Pa}, p \mathrm{CO}_{2}=2 \cdot 10^{4} \mathrm{~Pa}$.

\section{Conclusions}

An elementary kinetic model of CO electrochemical oxidation at Ni/YSZ electrodes was developed and validated. By solving reaction-diffusion equations on both $\mathrm{Ni}$ electrode and YSZ electrolyte surfaces, experimental data of well-defined Ni/YSZ patterned anodes were successfully reproduced over a wide range of $\mathrm{CO} / \mathrm{CO}_{2}$ gas composition and operating temperatures. In contrast to commonly used Butler-Volmer kinetics, which is based on global reactions and charge transfer, the representation of all chemical processes in terms of elementary reactions allows for predictive simulations of the complex behavior of Ni/YSZ patterned anodes. Furthermore, elementary kinetics opens up the possibility of a direct mechanistic interpretation of the experimentally observed electrochemical characteristics. In the case of $\mathrm{CO}$ oxidation, this allowed to identify a change in reaction mechanism as a function of $\mathrm{CO} / \mathrm{CO}_{2}$ ratio.

\section{Acknowledgments}

Financial support by the German Research Foundation (DFG) under grant numbers BE 3819/1-1 and VO 642/2-1 is gratefully acknowledged. H.-R. Volpp and V. Yurkiv would like to thank the International Graduate College (IGK 7110) "Complex Processes: 
Modeling, Simulation and Optimization" and the Heidelberg Graduate School of Mathematical and Computational Methods for the Sciences at the Interdisciplinary Center for Scientific Computing (IWR) for financial support. W. G. Bessler acknowledges funding by the Initiative and Networking Fund of the Helmholtz Association. Thanks are due to Dr. A. Gorski (Heidelberg University) and Dr. M. Vogler (German Aerospace Center, Stuttgart) for many fruitful discussions.

\section{References}

1. E. S. Hecht, G. K. Gupta, H. Y. Zhu, A. M. Dean, R. J. Kee, L. Maier and O. Deutschmann, Applied Catalysis a-General, 295, 40 (2005).

2. M. Vogler, A. Bieberle-Hutter, L. Gauckler, J. Warnatz and W. G. Bessler, J. Electrochem. Soc., B663 (2009).

3. D. G. Goodwin, H. Y. Zhu, A. M. Colclasure and R. J. Kee, J. Electrochem. Soc., 156, B1004 (2009).

4. A. Gorski, V. Yurkiv, D. Starukhin, H.-R. Volpp, J. Power Sources, doi:10.1016 / j.jpowsour.2010.09.090 (2010).

5. W. G. Bessler, M. Vogler, H. Störmer, D. Gerthsen, A. Utz, A. Weber and E. Ivers-Tiffée, Phys. Chem. Chem. Phys., 12, 13888 (2010).

6. V. Yurkiv, D. Starukhin, H.-R. Volpp and W. G. Bessler, J. Electrochem. Soc., 158, B5 (2011).

7. G. O. Lauvstad, R. Tunold and S. Sunde, J. Electrochem. Soc., 149, E506 (2002).

8. A. Utz, A. Leonide, A. Weber. and E. Ivers-Tiffee, J. Power Sources, doi:10.1016/j.powsour. 20.10.056 (2010)] (2010).

9. A. M. Sukeshini, B. Habibzadeh, B. P. Becker, C. A. Stoltz, B. W. Eichhorn and G. S. Jackson, J. Electrochem. Soc., 153, A705 (2006).

10. A. Utz, A. Weber, E. Ivers-Tiffée, H. Störmer, in R. Steinberger-Wilckens and U. Bossel (Eds.), Proceedings of the 8th European Solid Oxide Fuel Cell Forum, A0509 (2008).

11. A. Utz, H. Störmer, A. Leonide, A. Weber, E. Ivers-Tiffée, ECS Trans., 25, 2013-2021 (2009).

12. A. Utz, K. V. Hansen, K. Norrman, E. Ivers-Tiffée, M. Mogensen, Solid State Ionics, submitted (2010).

13. H. Störmer, A. Utz, E. Ivers-Tiffée,D. Gerthsen, in P. Connor, J. T. S. Irvine, M. Cassidy, C. Savaniu, M. Smith, and S. Knowles (Eds.), Proceedings of the 9th European SOFC Forum, 5-122-5-127 (2010).

14. W. G. Bessler, S. Gewies and M. Vogler, Electrochimica Acta, 53, 1782 (2007).

15. W. G. Bessler, J. Electrochem. Soc., 154, B1186 (2007).

16. P. Deuflhard, E. Hairer and J. Zugck, Numerische Mathematik, 51, 501 (1987).

17. A. Utz, H. Stormer, A. Leonide, A. Weber and E. Ivers-Tiffee, Journal of the Electrochemical Society, 157, B920 (2010).

18. V. Sonn, A. Leonide, E. Ivers-Tiffee, ECS Trans., 7, 1363 (2007).

19. F. A. Kroger, H. J. Vink, in F. Seitz, D. Turnbull (Eds.), Solid State Physics Advances in Research and Applications, Academic Press, New York, NY, 431 (1956).

20. A.Gorski, V. Yurkiv, W. G. Bessler and H.-R. Volpp, ECS Trans. (2011). 